\title{
Synthesis and bioactivity of analogues of the marine antibiotic tropodithietic acid
}

\author{
Patrick Rabe ${ }^{1}$, Tim A. Klapschinski ${ }^{1}$, Nelson L. Brock ${ }^{1}$, Christian A. Citron ${ }^{1}$, \\ Paul D'Alvise ${ }^{2}$, Lone Gram ${ }^{2}$ and Jeroen S. Dickschat ${ }^{* 1}$
}

\section{Letter}

Address:

${ }^{1}$ Kekulé-Institut für Organische Chemie, Rheinische

Friedrich-Wilhelms-Universität Bonn, Gerhard-Domagk-Straße 1,

53121 Bonn, Germany and ${ }^{2}$ Department of Systems Biology,

Technical University of Denmark, Matematiktorvet bldg. 301, 2800

Kongens Lyngby, Denmark

Email:

Jeroen S. Dickschat ${ }^{*}$ - dickschat@uni-bonn.de

* Corresponding author

Keywords:

antibiotics; natural products; Roseobacter, SAR study; tropodithietic acid; tropone

\author{
Beilstein J. Org. Chem. 2014, 10, 1796-1801. \\ doi:10.3762/bjoc. 10.188 \\ Received: 17 April 2014 \\ Accepted: 22 July 2014 \\ Published: 06 August 2014 \\ This article is part of the Thematic Series "Natural products in synthesis \\ and biosynthesis". \\ Associate Editor: K. N. Ganesh \\ (C) 2014 Rabe et al; licensee Beilstein-Institut. \\ License and terms: see end of document.
}

\begin{abstract}
Tropodithietic acid (TDA) is a structurally unique sulfur-containing antibiotic from the Roseobacter clade bacterium Phaeobacter inhibens DSM 17395 and a few other related species. We have synthesised several structural analogues of TDA and used them in bioactivity tests against Staphylococcus aureus and Vibrio anguillarum for a structure-activity relationship (SAR) study, revealing that the sulfur-free analogue of TDA, tropone-2-carboxylic acid, has an antibiotic activity that is even stronger than the bioactivity of the natural product. The synthesis of this compound and of several analogues is presented and the bioactivity of the synthetic compounds is discussed.
\end{abstract}

\section{Introduction}

Tropodithietic acid (TDA, 1a) is an antibiotic produced by the marine bacterium Phaeobacter inhibens. It has an unusual structure that is made up by a dithiet moiety fused to tropone-2carboxylic acid (Figure 1) [1]. In Phaeobacter the compound is accompanied by hydroxy-TDA 2, while its tautomer thiotropocin (1b) was previously reported from Pseudomonas [2,3]. The biosynthesis of 1 starts from phenylalanine and requires the paaABCDE and paaG genes of the upper phenylacetic acid (PAA) catabolon [4,5], the six genes $t a A B C D E F$ that are located on a plasmid [6,7], and the adjacent paaZ2 gene [8], a mutated copy of paaZ from the PAA catabolon. Particularly interesting is the mechanism of sulfur introduction that we have recently investigated in a study combining gene knockouts and feeding experiments with ${ }^{34}$ S-labelled amino acids [8]. In this study we could show that $S$-thiocysteine is the direct sulfur precursor of TDA. The introduction of sulfur proceeds via nucleophilic attack of $S$-thiocysteine to the Michael acceptor of tropone-2-carboxylic acid coenzyme A ester and oxidative 
elimination of cysteine. The second sulfur atom is introduced by analogous attack to the vinylogous Michael acceptor. The volatiles tropone (3) and tropone hydrate $\mathbf{4}$ can also be detected in $P$. inhibens headspace extracts and are shunt products of the TDA biosynthetic pathway [9]. Clardy and coworkers have recently reported on a series of structurally related compounds with algicidal activity, represented by roseobacticide A (5), but their biosynthesis is unknown [10].<smiles>C=C=C</smiles>

$1 \mathrm{a}$<smiles>O=c1cccccc1</smiles>

3<smiles>O=c1osc2c(=S)cccc(O)c12</smiles>

$1 b$<smiles>O=C(O)c1c(=O)ccc(O)c2ssc12</smiles>

2

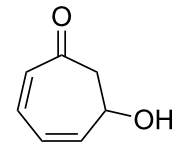

4

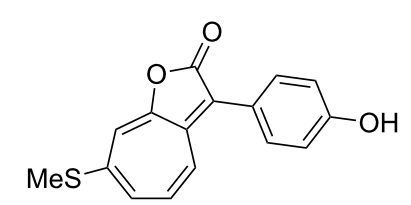

5
Figure 1: TDA and related natural products from Phaeobacter inhibens.

TDA exhibits a strong antibiotic activity against a broad spectrum of bacteria including alpha- and gammaproteobacteria, flavobacteria and actinobacteria [11], but not against the eukaryotic model organisms Artemia sp. and Caenorhabditis elegans, suggesting $P$. inhibens or other TDA-producing bacteria from the Roseobacter clade as promising candidates to be used as probiotics in aquacultures [12]. The mode of action of TDA is unknown, but it is difficult to select resistant and tolerant strains from long-term exposures to sub inhibitory concentrations of TDA, suggesting that TDA may interact with several targets [13]. Here we report on the synthesis and bioactivity of several TDA analogues for investigating the structure-activity relationship (SAR) of this unique marine antibiotic.

\section{Results and Discussion Synthesis of analogues of tropodithietic acid} For a detailed SAR study we first aimed at a series of compounds with a seven-membered carbocyclic core and an overall simplified structure as compared to the antibiotic TDA. Therefore, tropone-2-carboxylic acid (13), lacking the unprecedented dithiet moiety of TDA, was synthesised according to Scheme 1. Cyclohexenone 6 was first converted with NaHMDS and TMSCl into the corresponding silylenol ether that upon oxidation with $m$-CPBA under migration of the TMS group yielded the protected hydroxy ketone 7 . Aldol reaction with tert-butyl acetate to 8a and deprotection with TBAF gave 9a in 24\% yield over four steps. Oxidative cleavage of the glycol with $\mathrm{NaIO}_{4}$ resulted in a $\beta$-ketoester aldehyde that upon treatment with silica gel underwent an intramolecular aldol condensation to a mixture of 10a and 11a that were separable by column chromatography. Oxidation with DDQ gave tert-butyl tropone-2carboxylate (12a) that was efficiently converted into 13 by stirring in TFA. The synthesis of 12a followed a previously published route for ethyl tropone-2-carboxylate (12b) [14], but saponification of this ester led to decomposition, and therefore, the tert-butyl ester 12a was prepared that allowed for a conversion into 13 under acidic conditions.

Furthermore, a series of TDA analogues all with a sevenmembered carbocyclic core bearing a carbonyl function, a carboxylic acid or ester function in 2-position, and various functional groups such as halogen atoms and methoxy groups was synthesised (Scheme 2). Acrolein (14) was reacted with tertbutyl acetate (15) and LDA to yield the aldol product $\mathbf{1 6}$ that

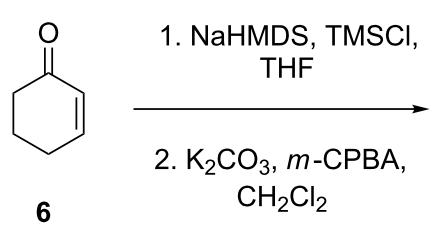<smiles>COC1CCC=CC1=O</smiles>

7<smiles>[R]OC(C)=O</smiles><smiles>[R]OC(=O)CC1(O)C=CCCC1OS(C)(=O)=O</smiles>

$$
\begin{aligned}
& \mathbf{8 a}(\mathrm{R}=t-\mathrm{Bu}) \\
& \mathbf{8 b}(\mathrm{R}=\mathrm{Et})
\end{aligned}
$$

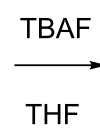

THF<smiles>[R]OC(=O)c1cccccc1=O</smiles>

TFA<smiles>O=C(O)c1cccccc1=O</smiles>

$13(90 \%$, from 12a)<smiles>[R]OC(=O)C1=CCCC=CC1=O</smiles>

DDQ, $\mathrm{NEt}_{3}$

$\mathrm{CH}_{2} \mathrm{Cl}_{2}$ 


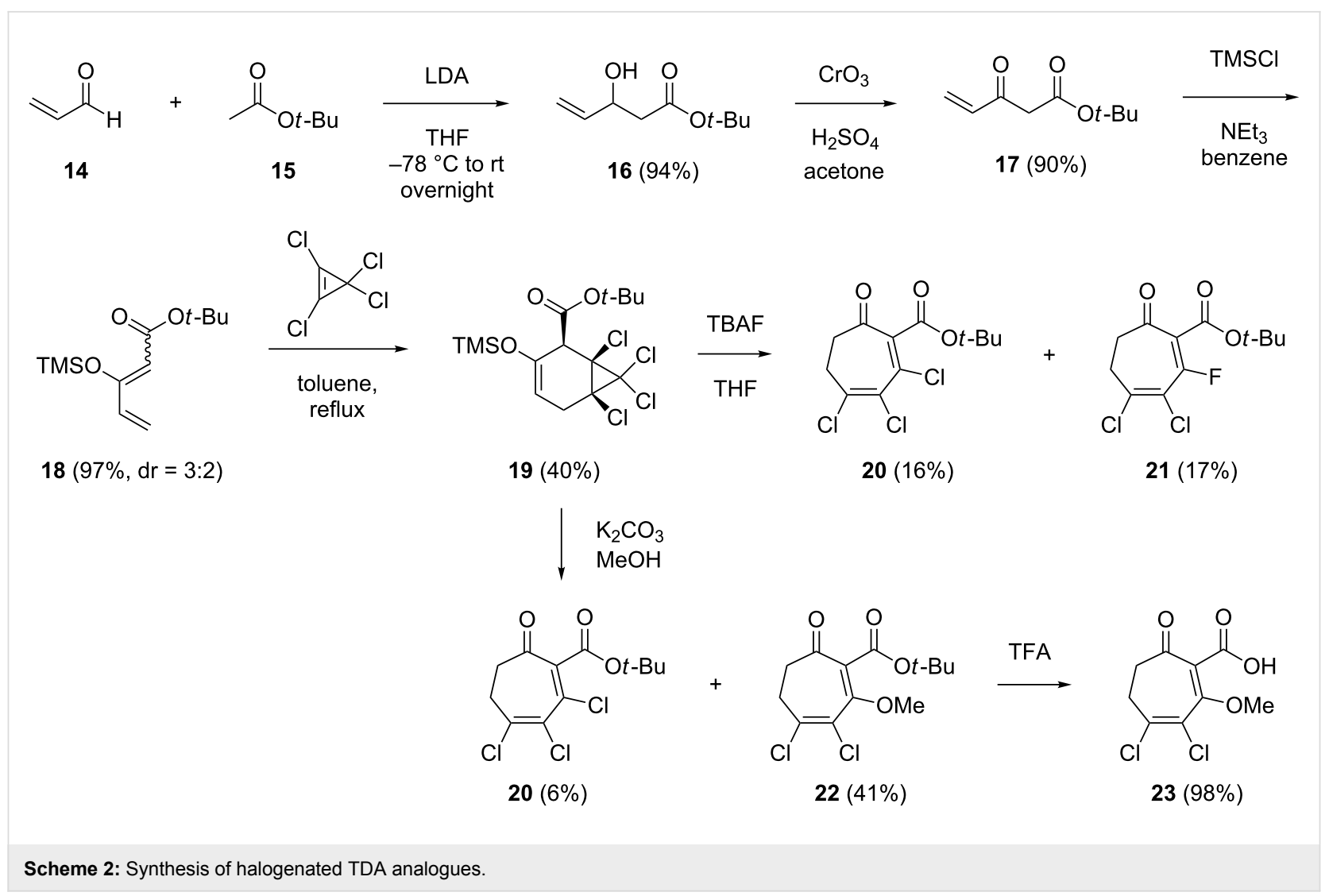

was subsequently oxidised to the $\beta$-keto ester $\mathbf{1 7}$ in a Jones oxidation. Treatment of the latter with TMSCl, imidazole and DMAP resulted in $\mathbf{1 8}$ as a 3:2 mixture of two diastereomers that proved to be unstable. However, the crude product was sufficiently pure for its direct usage in a Diels-Alder reaction with tetrachlorocyclopropene, resulting in the adduct $\mathbf{1 9}$ as a single stereoisomer. The formation of only one stereoisomer is explainable by an $E / Z$ isomerisation of $\mathbf{1 8}$ and a Diels-Alder reaction that only proceeds from $(Z)-\mathbf{1 8}$, but not from $(E)-\mathbf{1 8}$. Treatment of 19 with TBAF resulted in cleavage of the TMS protecting group followed by instantaneous elimination of $\mathrm{HCl}$ under cyclopropane ring opening to $\mathbf{2 0}$ with $16 \%$ yield. Furthermore, similar amounts of the fluorinated derivative 21 (17\%) were isolated. Its formation is explained by the nucleophilic attack of fluoride to the Michael acceptor in $\mathbf{2 0}$ followed by elimination of chloride. In contrast, treatment of $\mathbf{1 9}$ with potassium carbonate in $\mathrm{MeOH}$ yielded only minor amounts of $\mathbf{2 0}$ and the substitution product, methoxy derivative $\mathbf{2 2}$, as main product. All three compounds 20-22 were treated under various oxidation conditions (including DDQ, IBX, $\mathrm{SeO}_{2}$, and $\mathrm{MnO}_{2}$ ) to install the tropone moiety by dehydrogenation, but unfortunately all these reaction conditions failed. Compound $\mathbf{2 2}$ was subsequently converted into the free acid $\mathbf{2 3}$ by treatment with TFA, while similar conversions of $\mathbf{2 0}$ and $\mathbf{2 1}$ were unsuccessful due to the instability of the products.
Two structurally related halogenated compounds lacking the carboxylic acid function as in TDA, 2,3,4-trichlorotropone (24) and 3,4,5-trichloro-6,7-dihydrotropone (25), were prepared through a known route (Scheme 3) [15]. Finally, a few cycloheptanone derivatives with rigorously simplified structures as compared to TDA were included in this study. The $\beta$-ketoester 27 containing a Michael acceptor was synthesised from methyl cycloheptanone-2-carboxylate (26) by oxidation with $\mathrm{Cu}(\mathrm{OAc})_{2}$ and $\mathrm{Pb}(\mathrm{OAc})_{2}$ according to a known procedure [16]. The compound cyclohept-2-en-1-one (28) is commercially available, while we have previously reported the synthesis of cyclohept-4en-1-one (29) that was identified in headspace extracts from streptomycetes [17].

\section{Bioactivity tests}

All synthetic compounds were screened in bioactivity tests towards two bacterial strains, the Gram-positive Staphylococcus aureus 8325 and the Gram-negative Vibrio anguillarum 90-11-287 (Table 1). These organisms were selected for our bioactivity tests, because $S$. aureus is a clinically important human pathogen and strains with resistances against multiple antibiotic drugs cause severe problems with nosocomial infections. The bioactivity against $V$. anguillarum is interesting from an ecological point of view, because $P$. inhibens was originally isolated from scallop rearings [18-20], suggesting that the 
<smiles>O=c1cccc(Cl)c(Cl)c1Cl</smiles>

24<smiles>O=C1C=C(Cl)C(Cl)=C(Cl)CC1</smiles>

25<smiles>COC(=O)C1CCCCCC1=O</smiles>

26

$$
\underset{\mathrm{Pb}(\mathrm{OAc})_{4}}{\stackrel{\mathrm{Cu}(\mathrm{OAc})_{2}}{\longrightarrow}}
$$

$$
27(87 \%)
$$

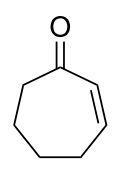

28

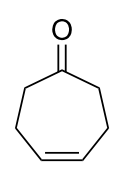

29
Scheme 3: Further compounds included in this SAR study.

natural function of $P$. inhibens may be to prevent molluscs from Vibrio infections.

Most of the compounds tested had minimal inhibitory concentrations (MICs) exceeding that of TDA, however, two com- pounds were of equal or even better antibiotic activity. Compound 25 was as effective, and tropone-2-carboxylic acid (13), closely resembling the structure of TDA, but lacking its sulfur atoms, was even more effective with a MIC corresponding to half the MIC of TDA (MIC against $S$. aureus was $26 \mu \mathrm{M}$ versus $39 \mu \mathrm{M}$, while the MIC against $V$. anguillarum was $6.5 \mu \mathrm{M}$ versus $19 \mu \mathrm{M})$. This indicates that the dithiet moiety of TDA is not essential for the direct antibacterial effect of the compound, and may have other physiological or ecological functions. This result is particularly surprising, because the coenzyme A ester of $\mathbf{1 3}$ is an intermediate along the biosynthetic pathway to TDA, so the question arises what may have been the evolutionary advantages of extending the biosynthetic pathway from the coenzyme A ester of $\mathbf{1 3}$ to TDA by the introduction of two sulfur atoms. A possible answer may be that TDA has more or other targets than $\mathbf{1 3}$ which may have the consequence that the development of resistances against TDA is prevented, thus offering an evolutionary advantage.

\section{Conclusion}

We have synthesised a series of compounds with sevenmembered carbocyclic rings. Their structures were inspired by the antibiotic TDA from the marine bacterium $P$. inhibens. One compound, 3,4,5-trichloro-5,6-dihydrotropone (25), showed a strong antibiotic activity against $S$. aureus and $V$. anguillarum

\begin{tabular}{|c|c|c|c|c|}
\hline \multirow[t]{2}{*}{ Compound $^{a}$} & \multicolumn{2}{|c|}{ Staphylococcus aureus 8325} & \multicolumn{2}{|c|}{ Vibrio anguillarum 90-11-287 } \\
\hline & $\mathrm{MIC} / \mathrm{mg} \mathrm{L}^{-1}$ & $\mathrm{MIC} / \mu \mathrm{M}$ & $\mathrm{MIC} / \mathrm{mg} \mathrm{L}^{-1}$ & $\mathrm{MIC} / \mu \mathrm{M}$ \\
\hline 1 & 7.8 & 39 & 3.9 & 19 \\
\hline $10 a$ & inactive & & 125 & 600 \\
\hline $10 \mathrm{~b}$ & 125 & 700 & 125 & 700 \\
\hline $11 \mathrm{a}$ & inactive & & 125 & 600 \\
\hline $12 a$ & 125 & 600 & 125 & 600 \\
\hline $12 b$ & 125 & 700 & 125 & 700 \\
\hline 13 & 3.9 & 26 & 1.0 & 6.5 \\
\hline 20 & inactive & & inactive & \\
\hline 21 & 125 & 430 & 125 & 430 \\
\hline 22 & inactive & & inactive & \\
\hline 23 & inactive & & inactive & \\
\hline 24 & inactive & & 125 & 720 \\
\hline 25 & 7.8 & 45 & 15.6 & 89 \\
\hline 26 & inactive & & inactive & \\
\hline 27 & 62.5 & 370 & 46.9 & 280 \\
\hline 28 & 62.5 & 570 & 31.3 & 280 \\
\hline 29 & 62.5 & 570 & 31.3 & 570 \\
\hline
\end{tabular}
that is similar to the activity of TDA, while tropone-2carboxylic acid (13) had an even stronger antibiotic effect. This

a MICs were determined using the microdilution method according to guidelines of the Clinical and Laboratory Standards Institute [21]. Compounds with MICs > $125 \mathrm{mg} \mathrm{L}^{-1}$ were regarded as inactive. 
suggests that the sulfur atoms in TDA are not essential for bioactivity, but different modes of action for TDA and its sulfur-free analogue cannot be excluded.

\section{Experimental}

Bioactivity testing. All synthetic compounds were used in bioactivity tests towards two bacterial strains, Staphylococcus aureus 8325 [22] and Vibrio anguillarum 90-11-287 [23] (Table 1). The two strains were grown as precultures overnight with agitation at $25^{\circ} \mathrm{C}$ in $20 \mathrm{~mL}$ cation-adjusted Mueller Hinton II Broth (Cat. No. 297963, Becton, Dickinson and Company, Sparks, MD, USA). The minimum inhibitory concentration (MIC) of the compounds was determined using the microdilution method according to the guidelines of the Clinical and Laboratory Standards Institute (CLSI 2006) [21]. All compounds were dissolved in DMSO to stock solutions of $1.5 \mathrm{~g} \mathrm{~L}^{-1}$ and further diluted in the bacterial growth medium, Mueller Hinton II Broth. Final concentrations ranging from 500 to $0.5 \mathrm{mg} \mathrm{L}^{-1}$ were tested and solvent controls were included.

\section{Supporting Information}

\section{Supporting Information File 1}

Synthetic procedures, compound characterisation data and copies of NMR spectra.

[http://www.beilstein-journals.org/bjoc/content/ supplementary/1860-5397-10-188-S1.pdf]

\section{Acknowledgements}

This work was funded by the Deutsche Forschungsgemeinschaft as part of the Transregional Collaborative Research Centre SFB-TR 51 ("Roseobacter"), by a PhD scholarship of the Beilstein-Institut zur Förderung der Chemischen Wissenschaften (to P.R.), and by a PhD scholarship of the Fonds der Chemischen Industrie (to N.L.B.).

\section{References}

1. Liang, L. Ph.D. Thesis, University of Göttingen, Germany, 2003.

2. Cane, D. E.; Wu, Z.; Van Epp, J. E. J. Am. Chem. Soc. 1992, 114, 8479-8483. doi:10.1021/ja00048a019

3. Greer, E. M.; Aebisher, D.; Greer, A.; Bentley, R. J. Org. Chem. 2008, 73, 280-283. doi:10.1021/jo7018416

4. Berger, M.; Brock, N. L.; Liesegang, H.; Dogs, M.; Preuth, I.; Simon, M.; Dickschat, J. S.; Brinkhoff, T. Appl. Environ. Microbiol. 2012, 78, 3539-3551. doi:10.1128/AEM.07657-11

5. Teufel, R.; Gantert, C.; Voss, M.; Eisenreich, W.; Haehnel, W.; Fuchs, G. J. Biol. Chem. 2011, 286, 11021-11034. doi:10.1074/jbc.M110.196667

6. Geng, H.; Bruhn, J. B.; Nielsen, K. F.; Gram, L.; Belas, L. Appl. Environ. Microbiol. 2008, 74, 1535-1545. doi:10.1128/AEM.02339-07
7. Thole, S.; Kalhoefer, D.; Voget, S.; Berger, M.; Engelhardt, T.; Liesegang, H.; Wollherr, A.; Kjelleberg, S.; Daniel, R.; Simon, M.; Thomas, T.; Brinkhoff, T. ISME J. 2012, 6, 2229-2244. doi:10.1038/ismej.2012.62

8. Brock, N. L.; Nikolay, A.; Dickschat, J. S. Chem. Commun. 2014, 50, 5487-5489. doi:10.1039/c4cc01924e

9. Thiel, V.; Brinkhoff, T.; Dickschat, J. S.; Wickel, S.; Grunenberg, J.; Wagner-Döbler, I.; Simon, M.; Schulz, S. Org. Biomol. Chem. 2010, 8, 234-246. doi:10.1039/b909133e

10. Seyedsayamdost, M. R.; Case, R. J.; Kolter, R.; Clardy, J. Nat. Chem. 2011, 3, 331-335. doi:10.1038/nchem.1002

11. Brinkhoff, T.; Bach, G.; Heidorn, T.; Liang, L.; Schlingloff, A.; Simon, M. Appl. Environ. Microbiol. 2004, 70, 2560-2565. doi:10.1128/AEM.70.4.2560-2565.2003

12. Neu, A. K.; Månsson, M.; Gram, L.; Prol-García, M. J. Appl. Environ. Microbiol. 2014, 80, 146-153. doi:10.1128/AEM.02717-13

13. Porsby, C. H.; Webber, M. A.; Nielsen, K. F.; Piddock, L. J. V.; Gram, L. Antimicrob. Agents Chemother. 2011, 55, 1332-1337. doi:10.1128/AAC.01222-10

14. Do, Y.-S.; Sun, R.; Kim, H. J.; Yeo, J. E.; Bae, S.-H.; Koo, S. J. Org. Chem. 2009, 74, 917-920. doi:10.1021/jo802064c

15. Seitz, G.; van Gemmern, R. Synthesis 1987, 953-956. doi:10.1055/s-1987-28139

16. Schultz, A. G.; Holoboski, M. A. Tetrahedron Lett. 1993, 34, 3021-3024. doi:10.1016/S0040-4039(00)93368-9

17. Citron, C. A.; Rabe, P.; Dickschat, J. S. J. Nat. Prod. 2012, 75, 1765-1776. doi:10.1021/np300468h

18. Ruiz-Ponte, C.; Cilia, V.; Lambert, C.; Nicolas, J. L. Int. J. Syst. Bacteriol. 1998, 48, 537-542. doi:10.1099/00207713-48-2-537

19. Martens, T.; Heidorn, T.; Pukall, R.; Simon, M.; Tindall, B. J.; Brinkhoff, T. Int. J. Syst. Evol. Microbiol. 2006, 56, 1293-1304. doi:10.1099/ijs.0.63724-0

20. Buddruhs, N.; Pradella, S.; Göker, M.; Päuker, O.; Pukall, R.; Spröer, C.; Schumann, P.; Petersen, J.; Brinkhoff, T. Int. J. Syst. Evol. Microbiol. 2013, 63, 4340-4349. doi:10.1099/ijs.0.053900-0

21. Wikler, M. A.; Cockerill, F. A.; Craig, W. A.; Dudley, M. N.; Eliopoulos, G. M.; Hecht, D. W.; Hindler, J. F.; Ferraro, M. J.; Swenson, J. M.; Low, D. E.; Sheehan, D. J.; Tenover, F. C.; Turnidge, J. D.; Weinstein, M. P.; Zimmer, B. L. Guideline M7-A7: Methods for dilution antimicrobial susceptibility tests for bacteria that grow aerobically; Approved Standard-Seventh Edition; Clinical Laboratory Standards Institute: Wayne, 2006.

22. Novick, R. Virology 1967, 33, 155-166. doi:10.1016/0042-6822(67)90105-5

23. Skov, M. N.; Pedersen, K.; Larsen, J. L. Appl. Environ. Microbiol. 1995, $61,1540-1545$. 


\section{License and Terms}

This is an Open Access article under the terms of the Creative Commons Attribution License

(http://creativecommons.org/licenses/by/2.0), which permits unrestricted use, distribution, and reproduction in any medium, provided the original work is properly cited.

The license is subject to the Beilstein Journal of Organic Chemistry terms and conditions:

(http://www.beilstein-journals.org/bjoc)

The definitive version of this article is the electronic one which can be found at:

doi:10.3762/bjoc. 10.188 